\title{
An in situ near-ambient pressure X-ray Photoelectron Spectroscopy study of Mn polarised anodically in a cell with solid oxide electrolyte
}

Benedetto Bozzini ${ }^{1 *}$, Matteo Amati ${ }^{2}$, Patrizia Bocchetta ${ }^{1}$, Simone Dal Zilio ${ }^{3}$, Axel Knop-Gericke ${ }^{4}$, Erik Vesselli ${ }^{3,5}$ and Maya Kiskinova ${ }^{2}$

${ }^{1}$ Dipartimento di Ingegneria dell'Innovazione, Università del Salento, via Monteroni s.n., 73100 Lecce, Italy

${ }^{2}$ Elettra - Sinctrotrone Trieste S.C.p.A. S.S. 14, km 163.5 in Area Science Park, 34149 TriesteBasovizza, Italy

${ }^{3}$ IOM-CNR S.S. 14, km 163.5 in Area Science Park, 34149 Trieste-Basovizza, Italy

${ }^{4}$ Abteilung Anorganische Chemie, Fritz-Haber-Institut der Max-Planck Gesellschaft, Faradayweg 4-6, 14195 Berlin (Germany)

${ }^{5}$ Department of Physics and CENMAT, University of Trieste, via Valerio 2, 34127 Trieste, Italy

*Corresponding author: benedetto.bozzini@unisalento.it telephone +39-0832-297323, fax +39-0832-297733.

\begin{abstract}
This paper reports an in situ study of the anodic behavior of a model solid oxide electrolysis cell (SOEC) by means of near-ambient pressure X-ray Photoelectron Spectroscopy (XPS) combined with near edge X-ray absorption fine structure (NEXAFS) measurements. The focus is on the anodic surface chemistry of $\mathrm{MnO}_{\mathrm{x}}$, a model anodic material already considered in cognate SOFCrelated studies, during electrochemical operation in $\mathrm{CO}_{2}, \mathrm{CO}_{2} / \mathrm{H}_{2} \mathrm{O}$ and $\mathrm{H}_{2} \mathrm{O}$ ambients. The XPS and NEXAFS results we obtained, complemented by electrochemical measurements and SEM characterisation, reveal the chemical evolution of $\mathrm{Mn}$ under electrochemical control. $\mathrm{MnO}$ is the stable chemical form at open-circuit potential potential (OCP), while $\mathrm{Mn}_{3} \mathrm{O}_{4}$ forms under anodic
\end{abstract}


polarisation in all the investigated gas ambients. Carbon deposits are present at the Mn electrode at OCP, but it is readily oxidised under anodic conditions. Prolonged operation of the $\mathrm{MnO}_{\mathrm{x}}$ anode leads to pitting of the Mn films, damaging of the triple-phase boundary region and also to formation of discontinuities in the Mn patch. This is accompanied by chemical transformations of the electrolyte and formation of $\mathrm{ZrC}$ without impact on the surface chemistry of the Mn-based anode.

\section{Keywords}

Mn; solid-oxide cell; near-ambient pressure XPS; near-ambient pressure NEXAFS

\section{Introduction}

Fundamental understanding of the surface chemistry of $\mathrm{O}_{2}$-evolving anodes in solid-oxide electrochemical cells is still a challenge and a key for improving the durability of promising energetic devices, such as SOECs, which is seriously impaired chiefly by degradation of the anodes. In material science the degradation of the SOEC components, governed by the particular chemistry and experimental conditions [1], is an universally recognised problem, and the anodes are the most sensible and predisposed to failures as result of damaging processes of various origin. Apart from Cr contamination, that is typical for systems employing ferritic stainless steel interconnects [2-8], two key mechanisms have been considered: (i) electrode delamination and (ii) cation migration and/or segregation of passivating species [9-15]. Delamination of the oxygen electrode seems to be due to the presence of large oxygen activity gradients that causes the formation of gaseous oxygen within the electrolyte close to the electrode/electrolyte interface, resulting in generation of nanoporosity at the grain boundaries. In fact, the loss of oxygen vacancies under anodic polarisation conditions of SOECs is reported to be a source of oxygen electrode deactivation [15]. According to the defect model [16], in real Sr-doped $\mathrm{LaMnO}_{3}$ (LSM) electrodes the highly oxidising anodic environment results in the oxidation of the manganese species with concomitant decrease of oxygen vacancy concentration to ensure electro neutrality. In-situ scanning photoelectron microscopy [17] 
has proven that the surface chemistry of LSM electrodes strongly depends on the polarisation mode: $\mathrm{Mn}(\mathrm{II})$ is predominant at highly cathodic potentials, while $\mathrm{Mn}(\mathrm{IV})$ forms under anodic SOFC conditions.

Notwithstanding the growing number of high-quality papers in the field of SOEC materials, the fundamental physico-chemical information is still not complete, in particular the surface chemistry of the electrodes under electrochemical polarisation warrants further investigations. Here we report a pioneering in-situ near-ambient pressure XPS and NEXAFS study of the behavior of nanometrically thick $\mathrm{Mn}$ film anodes of a $\mathrm{Cu}|\mathrm{YSZ}| \mathrm{Mn}$ cell (YSZ: yttria-stabilised zirconia) in $\mathrm{CO}_{2}$, $\mathrm{CO}_{2} / \mathrm{H}_{2} \mathrm{O}$ and $\mathrm{H}_{2} \mathrm{O}$ ambients. It should be noted that although the reported results have not immediate bearing on the engineering of SOECs, they have significant methodology impact paving the way towards future near-ambient pressure XPS and NEXAFS investigations of operating practical electrode materials.

In our previous XPS studies of SOFC model systems exploring processes occurring at microscopic length scales [2-4, 18-20], we have already demonstrated the suitability of the adopted cell geometry for in situ photoelectron spectroscopy measurements in reactive low gas pressure ambient and high temperature and the Mn thin film electrodes have been successfully employed for cognate SOFC-oriented studies $[19,20]$. The key methodological achievements in $[2-4,18-20]$ were taken for granted in the present study and therefore just the following aspects are briefly recalled for the readers' perusal: (i) the basic principles of the cell configuration; (ii) the chemical nature of the model electrode materials and (iii) the electrochemical significance of single-electrode operation in a given single-gas environment. It is worth noting that the unique potential of photoelectron spectroscopy and microscopy in the presence of electroactive gases has recently been demonstrated by a series of in situ SOFCs studies [2-4, 18, 21-24] and, in particular, of externally-driven systems, mimicking the operation of real devices $[19,20]$. In the present study of the surface chemistry of Mn thin film electrodes in contact with YSZ, we overcome the pressure gap by using near-ambient 
pressure gas chemistries, which is an essential step ahead to probing the behavior of the cell components under realistic operation conditions.

\section{Experimental}

\subsection{Cell fabrication}

In this study we used planar, YSZ(100)-supported cells with lithographically defined $\mathrm{Cu}$ and $\mathrm{Mn}$ thin-film electrodes. The cell geometry and electrode fabrication developed for this class of devices are described in $[2-4,19,20]$, will be only briefly explained in the following. Planar cells are chosen for two chief reasons: (i) to contain the whole cell chemistry (anode, electrolyte, cathode) accessible to the probe beam; (ii) to confine to the surface the regions of the electrochemical cell exhibiting the highest electrochemical reaction rate, so that the utmost surface sensitivity of photoelectron spectroscopy can be exploited at its best. In particular, the triple-phase boundaries are provided by the contact lines between electrode and electrolyte, exposed to the gas environment of the analysis chamber. The preference for model electrode materials, instead of real ones, is dictated by the need of demonstrating in this chiefly methodological work the feasibility of complex in-situ spectroscopy measurements at high temperature with lower reagent gases pressure. We would like to notify that in these model studies we follow the chemical evolution of a few, elements relevant to the electrode and electrolyte status under electrochemical control. They provide basic input for the processes that has to be considered for finding solution to optimise the electrocatalytic performance or the electrode durability. To sum up: the selection of the electrode material is a compromise amongst the following factors: (i) use of metal for ease of lithographic fabrication, which is transformed into oxides by suitable pretreatments or even by simple application of the working conditions in the analysis chamber [2-4, 18-20]; (ii) use of a single relevant element, in order not to widen the experimental parameter space that would not be manageable in a pilot study. In fact, the XAS and NEXAFS yield a wealth of sensitive chemical information and handling too many 
elements in a methodological study is inappropriate. Inspection of the relevant literature shows that the use of practical materials and stacked rather than planar cells configurations in photoelectronbased studies is not rewarding in terms of both electrochemical control and insight. Of course, future studies, based on the methodological achievements acquired with a model approach, will address also practical materials. In our specific case the material combination is the same as that of $[19,20]$, apart the replacement of $\mathrm{Ni}$ by $\mathrm{Cu}$ that is only ancillary to the study described here. As detailed in $[19,20,25]$ using $\mathrm{MnO}_{2} / \mathrm{Au}$ as an SOFC electrode material is dictated by the fact that: (i) $\mathrm{Mn}$ is a key element of several practical anode materials with a rich, relevant redox chemistry and (ii) it provides an ideal benchmark for in situ XPS and NEXAFS spectro-electrochemistry. The reason for considering $\mathrm{Cu}$ as a cathodic material (not being a scope of the present study) is that it is also an emerging element for SOEC cathodes $[26,27])$.

YSZ(100) single crystals $(1 \mathrm{~cm} \times 1 \mathrm{~cm} \times 1 \mathrm{~mm})$ were purchased from Mateck and used as cell support. As in $[19,20]$, the electrodes were fabricated by evaporating $70 \mathrm{~nm}$ thick $\mathrm{Cu}$ and Mn layers onto $\mathrm{Au}(30 \mathrm{~nm})$ contact layers grown onto $\mathrm{Cr}$ adhesion buffers $(10 \mathrm{~nm})$ (Figure 1-A). Figure 1-B shows the electrode dimensions and interelectrodic distance together with the location of the $\mathrm{Pt}$ current collectors. The principle of electrochemical operation of the cell is illustrated in Figure 1-C and will be detailed in Section 2.3. In order to achieve a high surface density of triple phase boundaries (TPB) with the lithographic approach, the electrodes were designed with a square lattice of circular holes, giving access to the YSZ (see Panels A and B of Figure 1). The hole diameter was nominally $4 \mu \mathrm{m}$ and allowed to sample a significant length of TPB lines under the probe beam, the diameter of which is ca. $150 \mu \mathrm{m}$ : representative SEM images of the electrodes of a pristine cell are shown in Panels (A.1), (A.2) and (A.3) of Figure 2. It is worth noting that the waviness of Panel (A.3) (see red line, for reference) is not a fabrication flaw, but an optical effect due to charging, since in pristine conditions YSZ is insulating at room temperature, while metal doping of the aged cells imparts some degree of room-temperature electronic conductivity, as one can assess from the micrographs of the aged cells. 
The model cell is placed inside the XPS chamber on a suitable sapphire sample-holder equipped with to proper electrical connections for controlled electrochemical polarisation (Figure 1-D) and a laser heater, capable of reaching high temperatures, as detailed in Section 2.3: the cell mounted on the sample stage inside the chamber is depicted in Figure 1-E.

\subsection{Electrochemical methods}

Electrochemical measurements in two-electrode configuration were carried out in the analysis chamber at the working temperature as a diagnostic tool of cell operation in the different gas environments under applied potential. The same approach has been inaugurated and justified in [19] and employed in [20] with a cell that, apart from the $\mathrm{Cu}$ electrode and the presence of holes in the electrode patches, is identical to that used for the present investigation. Owing to the special cell configuration adopted in this study that exhibits a very small active electrode area and high ohmic resistance, but nevertheless allowing ideal in situ photoelectron detection from all the cell components, we lay no claims to achieve quantitative electroanalytical results or to obtain absolute values,which can be compared with cognate ones measured with traditional methods and conventional electrochemical cells. In fact, the purpose of our electrochemical measurements is threefold: (i) to prove that the cell operates in the expected way during spectroscopy; (ii) to detect changes under electrochemical conditions and (iii) to gain relative electrokinetic information regarding the operation in different gases and at different potentials. To this aim, we carried out linear-sweep voltammetry (LSV), potentiostatic polarisation and electrochemical impedance spectrometry (EIS) measurements. In particular, in order to gain integral (i.e. from our two electrode configuration, of course yielding electrokinetic data deriving from the whole cell) comparative (i.e. as a function of operating time, gas environment and applied polarisation) electrochemical information on the behaviour of the cells, we periodically measured EIS spectra at open circuit potential (OCP). We employed a Versastat potentiostat and data were acquired with the Versastudio software. As emphasised above, EIS data were fitted in order to gain comparative 
information on the different types of environment and operating conditions employed: it is important to note that in this particular research, comparison of our parameter values with cognate literature outcomes is not relevant. The EIS data analysis and the equivalent circuit fitting have been performed with the EIS Spectrum Analyzer software [28], non-linear least-squares optimisation is performed with the amplitude-weighted objective function reported in Eq. (1):

$$
r_{c}^{2}=\sum_{i=1}^{N} \frac{\left(Z_{i}^{\prime}-Z_{i}^{\prime}{ }_{\text {calc }}\right)^{2}+\left(Z_{i}^{\prime \prime}-Z_{i}^{\prime \prime} \text { calc }\right)^{2}}{Z_{i}^{\prime 2}+Z_{i}^{\prime \prime}}
$$

where $Z_{i}$ and $Z_{i, \text { calc }}$ for $i=1, \ldots, N$ correspond, respectively, to measured and computed impedance values. The estimated values of $r^{2}$ are reported in Figures 3, 4. The EIS spectra were fitted with the typical equivalent circuit model used for SOEC consisting of a series resistance and up to five $R Q$ parallels, as proposed in [29-32], for a two-electrode configuration, instrumentally analogous to that relevant to our study. Where required, one the of $Q$ elements has been replaced with a Warburg impedance [5]. The particular circuits we used in individual instances are reported in the captions of Figures 3, 4. For the diagnostic reasons detailed at the beginning of this Section, in this study we implemented the electrochemical characterisation and operation protocol detailed below. (i) LSV in the range OCP-2V for pristine cells; (ii) potentiostatic operation at $2 \mathrm{~V}$ for pristine cells; (iii) EIS at OCP after representative electrochemical polarisation sequences, in particular in order to obtain information on the evolution of the cell as a result of prolonged operation. For compactness of presentation, we shall refer to voltage with its absolute cell value, considering that the $\mathrm{Mn}$ and $\mathrm{Cu}$ patches have always been polarised anodically and cathodically, respectively.

\subsection{Near-ambient pressure XPS and NEXAFS}

The cells were initially exposed to 0.5 mbar of either $\mathrm{CO}_{2}$ (Figure 1-C.1) or $\mathrm{CO}_{2} / \mathrm{H}_{2} \mathrm{O}$ 1:1 (Figure 1C.2) at room temperature and subsequently they were brought to the operating temperature of $600^{\circ} \mathrm{C}$. Subsequently the gas environment was switched, at the same pressure, from $\mathrm{CO}_{2} / \mathrm{H}_{2} \mathrm{O} 1: 1$ ambient to $\mathrm{CO}_{2} / \mathrm{H}_{2} \mathrm{O} 1: 2$ and pure $\mathrm{H}_{2} \mathrm{O}$ (Figure 1-C.3). In this study, centred on the anodic 
behaviour of $\mathrm{Mn}$ in $\mathrm{CO}_{2}$ - and $\mathrm{H}_{2} \mathrm{O}$-containing gas ambients, we concentrated on XPS of the $\mathrm{C} 1 \mathrm{~s}$, O $1 \mathrm{~s}, \mathrm{Mn} 2 \mathrm{p}$ and $\mathrm{Zr} 3 \mathrm{~d}$ core levels and NEXAFS at the Mn L-edge and O K-edge and carried out potential-dependent spectroscopy in the above-listed gas environments. The experiments were carried out at the ISISS beamline of the BESSY-II Synchrotron in Berlin. This dipole magnet beamline is dedicated to near-ambient pressure X-ray photoelectron and X-ray absorption spectroscopies in the field of materials science in general and catalysis in particular [33]. Since the experimental set-up using applied potentials interferes with the measurement of the sample currents as well as with the secondary electron signal, NEXAFS spectroscopy was performed by following the changes of the XPS and Auger signal while scanning the photon energy. Thus, the XPS and NEXAFS spectra probe comparable sample depths, relevant exclusively to the surface and nearsurface chemical states. The beamline set-up, including a Petersen-type plane grating monochromator (PGM) operating with collimated light, ensures state-of-the-art performance over the whole broad operation range from $80-2000 \mathrm{eV}$ with a photon flux up to $1.5 \times 10^{11}$ photons/s at $100 \mathrm{~mA}$ and a resolving power up to 30000 at $400 \mathrm{eV}$. The focus size is $100 \mu \mathrm{m} \times 80 \mu \mathrm{m}$ (horizontal $\times$ vertical). The XPS signal was calibrated with respect to the $\mathrm{Au} 4 \mathrm{f}$ internal reference (see Section 2.1) and normalised before fitting with Doniach-Šunjić lineshapes, convoluted with a Gaussian envelope and with the addition of a linear background [34]. It is worth noting that, as a direct proof of the perfect electrochemical control of our experiments, the XPS spectra exhibit the electrochemical shifts - proved and discussed in $[3,4,20,22,23]$ - that are a direct measurement of the local overvoltage. A detailed discussion of these effects and of their electrokinetic bearing is beyond the scope of the present paper - mainly concerned with chemical speciation - and, for clarity of presentation, the energy has been calibrated with respect to the OCP value. 


\section{Results and discussion}

Since the aim of this investigation is to observe and rationalise the dynamic anodic surface electrochemistry of Au-supported Mn films forming a TPB with YSZ electrolyte and a reactive gas phase, our in situ near-ambient pressure XPS and NEXAFS experiments explored the behaviour of the oxygen-evolving electrode in three representative environments of SOEC operation: $\mathrm{CO}_{2}$ and $\mathrm{H}_{2} \mathrm{O}$ electrolysis and $\mathrm{CO}_{2}+\mathrm{H}_{2} \mathrm{O}$ co-electrolysis. Of course, in a practical SOEC, the anodic material would be different (typically LSM) and under normal operation would not be in contact with the cathodic reagents, nevertheless the anodic reaction - though with a different $\mathrm{O}_{2}$ activity - would be the same. Moreover, the presence of $\mathrm{H}_{2} \mathrm{O}$ and $\mathrm{CO}_{2}$ in the gas phase feed has been recently reported to have potential impact on the material stability in both SOFCs [35] and SOECs [36]. The experiments were organised according to the following protocol. First we studied the cell under $\mathrm{CO}_{2}$ electrolysis in the following electrochemical conditions: (i) OCP, (i) mild working condition (2 V) and (i) stress condition (4 V). Second we carried out experiments in $\mathrm{CO}_{2} / \mathrm{H}_{2} \mathrm{O}$ ambient in the following sequence: (i) a pristine cell was placed in $1: 1 \mathrm{CO}_{2} / \mathrm{H}_{2} \mathrm{O}$ environment and polarised at $2 \mathrm{~V}$ for a total period of 28 hours; (ii) the gas $\mathrm{CO}_{2} / \mathrm{H}_{2} \mathrm{O}$ ratio was changed to $1: 2$ and to pure $\mathrm{H}_{2} \mathrm{O}$ under the same polarization conditions.

\subsection{Monitoring of cell conditions}

Electrochemical measurements were employed in order to monitor the conditions of the electrochemical cells during in situ spectroscopy. To this end we have first carried out a series of measurements on pristine cells, in order to acquire reference data (Section 3.1.1), and then we have followed the cell evolution during the beamtime, in view of associating a given spectroscopic state to the degree of ageing (Section 3.1.2). Eventually, the final cell conditions were assessed by SEM imaging (Section 3.1.3). 
3.1.1 Electrochemical measurements with pristine cells - In order to qualify the overall electrochemical behavior of the cells at the working temperature in the three gas environments considered, LSV curves (Figure 3, Panel A) and EIS spectra (Figure 3, Panels E, F) of pristine cells have been measured in a mock-up of the analysis chamber (Figure 3, Panels B-D) ensuring operating conditions identical to those of spectroscopy. It is worth noting that, owing to the special nature of our TPB geometry, with the same approach adopted in [2-4, 18-20], it is more significant to report the cell current than the current density: cell fabrication by lithography allows remarkable reproducibility of the geometry and the comparative value of our current measurements is thus ensured.

The LSV reported in Figure 3-A (black line), for a pristine $\mathrm{SOEC}$ in $\mathrm{CO}_{2}$ environment, indicates that the process is under mixed control and a change in mechanism, corresponding to an initial increase in reaction rate followed by the development of a secondary inhibition process, can be observed at ca. 1.2 V, the voltage required for the oxidation of $\mathrm{C}$ adsorbed at OCP at the $\mathrm{Cu}$ cathode in pure $\mathrm{CO}_{2}$ : more details will be provided in a separate paper concentrating on the behavior of the $\mathrm{Cu}$ cathode. In pure $\mathrm{H}_{2} \mathrm{O}$ (Figure $3-\mathrm{A}$, red line) one can observe a notably higher activity with respect to the $\mathrm{CO}_{2}$ ambient, related to the absence of electrodically adsorbed carbon species. Eventually, the LSV behavior in $\mathrm{CO}_{2} / \mathrm{H}_{2} \mathrm{O}=1 / 1$ (Figure 3-A, green line) does not show changes in reaction mechanism related to $\mathrm{C}$ desorption and the observed c.d.s are the highest among the three studied systems, indicating that both reduction reactions are running, even though not independently, since the observed c.d. is only $50 \pm 6 \%$ of the sum of the single $\mathrm{CO}_{2}$ and $\mathrm{H}_{2} \mathrm{O}$ electrolysis.

EIS spectra with pristine cells in the three considered gas environments were recorded at a bias of 2 V after 30 min of stabilisation (Figure 3, Panels E, F). In all ambients the spectra exhibit a similar Nyquist behavior consisting in a series of $R Q$ loops. The exact nature of the single processes described by the $R Q$ parallels of the whole cell in two-electrode configuration cannot be conclusively established, nevertheless SOEC modeling of these measurements is available in the literature [29-32], on which we shall base the interpretation of our data. Accordingly, the intercept 
of the impedance spectra with the real axis at high frequency corresponds to the ohmic resistance $\left(R_{o h m}\right)$ of the cell, the high frequency arcs $\left(R_{1} Q_{1}, R_{2} Q_{2}\right)$ to faradic processes at the electrode/electrolyte interface [37, 38], the medium frequency arc $\left(R_{3} Q_{3}\right)$ to gas diffusion (anode) and/or $\mathrm{O}_{2}{ }^{-}$ions transport (anode) and/or gas conversion (cathode) [5], while the low-frequency loop $\left(R_{4} Q_{4}\right)$ refers to gas-phase diffusion at the cathode [37, 38]. From Figure 3, Panels E, F, it can be noted that in pure $\mathrm{H}_{2} \mathrm{O}$ (red plot) environment the $R Q$ loops are smaller than those found with pure $\mathrm{CO}_{2}$ (black plot), coherently with the corresponding LSV curves. The decrease of the chargetransfer impedance ( $R_{1}$ from 11850 to $11000 \Omega ; R_{2}$ from 40300 to $92 \Omega$ ) in the presence of $\mathrm{H}_{2} \mathrm{O}$ is commonly attributed to the higher diffusivity and adsorption capacitance of $\mathrm{H}_{2} \mathrm{O}$ with respect to $\mathrm{CO}_{2}[31,39,40]$.

\subsubsection{Electrochemical measurements during spectroscopy - In situ XPS and NEXAFS spectroscopy} measurements were carried potentiostatically over extended periods of time, likely to bring about changes in the cell materials and electrochemical behavior. In order to track changes in cell behaviour and assess their impact on the surface chemistry, we measured EIS spectra at OCP after appropriate series of spectroscopic measurements at different cell potentials ( 2 and $4 \mathrm{~V})$, typically lasting, unless otherwise stated, 6 hours. In $\mathrm{CO}_{2}$ ambient (Figure 4-A) it can be observed that after 6 hours at $2 \mathrm{~V}$, a notable change in EIS shape occurs, characterised by a strong increase in the ohmic resistance $R_{o h m}$ (from 25 to $2800 \Omega$ ) and the charge-transfer resistance $R_{1}$ (from 580 to $13100 \Omega$ ) as well as by the appearance of a mass-transport controlled response at low frequencies corresponding to a new parallel $R_{5} W_{5}$ in the equivalent circuit [30] (Figure 4-A). The observed increase in $R_{\text {ohm }}$ can be associated to the increase in porosity and cracking at YSZ grain boundaries due to oxygen formation at the $\mathrm{Mn} / \mathrm{YSZ}$ interface, while the concomitant $R_{1}$ increase can be attributed to the delamination process occurring at the Mn anode ([30] and refs. therein). The presence of the new $R_{5} W_{5}$ parallel suggests that, in addition to gas diffusion, also the surface diffusion of $\mathrm{O}^{2-}$ vacancies can be involved in the reaction mechanism [31]. Application of the stress conditions at $4 \mathrm{~V}$ resulted 
in an important restructuring of the impedance spectrum with a reduction in ohmic resistance ( $R_{o h m}=650 \Omega$ ), the disappearance of the $R_{5} W_{5}$ diffusive contribution and the appearance of much faster faradaic $R Q$ loops ( $R_{1}$ : from 13100 to $350 \Omega$; $R_{2}$ : from 600 to $25 \Omega$ ): these mechanism changes can be attributed to the diffusion of $\mathrm{Mn}$ in the electrolyte patch (see also Figure 2) and the formation of metal islands, coherently with the XPS results and the SEM observations discussed below.

Figure 4-B reports EIS spectra measured under different ageing conditions in $\mathrm{CO}_{2} / \mathrm{H}_{2} \mathrm{O}$ and $\mathrm{H}_{2} \mathrm{O}$. After the first period of 28 hours of operation at $2 \mathrm{~V}$ in $\mathrm{CO}_{2} / \mathrm{H}_{2} \mathrm{O} 1 / 1,1 / 2$ and $\mathrm{H}_{2} \mathrm{O}$ the series resistance $\left(R_{\text {ohm }}\right)$ was found to increase (from 1150 to $3150 \Omega$ in $\mathrm{CO}_{2} / \mathrm{H}_{2} \mathrm{O}$ 1/1) and to attain an asymptotic value, essentially common to both gas ambients $\left(R_{\text {ohm }}: 3100 \Omega\right.$ in $\mathrm{CO}_{2} / \mathrm{H}_{2} \mathrm{O} 1 / 2$ and $3300 \Omega$ in $\mathrm{H}_{2} \mathrm{O}$ ). In $\mathrm{CO}_{2} / \mathrm{H}_{2} \mathrm{O}=1 / 1$, comparing the pristine and aged conditions, the $R_{1}$ and $R_{2}$ polarisation resistances increase $\left(R_{1, \text { pristine }}=820 \Omega, R_{1, \text { aged }}=980 \Omega ; R_{2, \text { pristine }}=2400 \Omega, R_{2, \text { aged }}=11500\right.$ $\Omega$ ). While $C P E_{1}$ exhibits pure capacitive properties ( $n$ ca. 1) irrespective of aging, $C P E_{2}$ changes from a pure capacitive behaviour in pristine conditions ( $\mathrm{n}$ ca. 1$)$ to a more resistive one $(\mathrm{n}=0.33)$ denoting the formation of electrode inhomogeneities or surface roughening and a non uniform current distribution at the surface. Moreover, a notable decrease in the resistance $R_{3}$ can also be noticed and the corresponding $C P E_{3}$ changes to a Warburg-type behavior $\left(n_{3, p r i s t i n e}=0.84 ; n_{3, \text { aged }}=\right.$ 0.55) indicating the presence of diffusion-limited processes [31]. When the $\mathrm{CO}_{2}$ to $\mathrm{H}_{2} \mathrm{O}$ ratio was lowered to $1 / 2$, only the charge transfer resistances $R_{2}, R_{3}$ and the gas-phase diffusion resistance $R_{4}$ were found to increase, while the other parameters of the circuit remain essentially constant. The EIS spectrum measured after having polarised the cell in pure $\mathrm{H}_{2} \mathrm{O}$ at $2 \mathrm{~V}$ for 9 hours indicates that the incremental changes in electrochemical behaviour are limited, as one can appreciate from the slight variation of the equivalent circuit parameters. 
3.1.3 SEM imaging - Figure 2 reports SEM micrographs of the Mn electrode in pristine conditions (A, see other comments regarding fabrication in Section 2.1) as well as after operation in $\mathrm{CO}_{2}$ (B) and $\mathrm{CO}_{2}+\mathrm{H}_{2} \mathrm{O}(\mathrm{C})$. Panels A.1, B.1 and C.1 show a typical region inside the electrolyte patch, Panels A.2, B.2 and C.2 are blow-ups of a single lithographed hole and Panels A.3, B.3 and C.3 show the interface between the YSZ and Mn patches. The morphological evolution of the electrode and electro-electrolyte interfaces - associated with prolonged anodic operation - can be appreciated. The main degradation modes, common to both gas environments, are extensive pitting within the Mn patch and diffusion of metal into the electrolyte region, as one can notice from the compositional contrast in the YSZ regions of the pristine and aged cells. In pure $\mathrm{CO}_{2}$ (Panels B.1, B.2 and B.3), the holes giving way to the underlying electrolyte have increased their diameter by a factor of ca. 1.4 and the pits at the original TPB are generally larger than the ones formed in the middle of the area originally covered with the Mn film. In $\mathrm{CO}_{2}+\mathrm{H}_{2} \mathrm{O}$ ambient, the TPBs seem less attacked that in pure $\mathrm{CO}_{2}$ environment while the interface between the $\mathrm{YSZ}$ and Mn patches (Panel C.3) shows a clear delamination, coherently with literature reports of the failure of the anode/electrolyte interface in SOECs $[5,15]$.

\subsection{In situ XPS and NEXAFS}

In order to investigate the electrochemical behaviour of the $\mathrm{Mn}$ anode in $\mathrm{CO}_{2}, \mathrm{H}_{2} \mathrm{O}$ and $\mathrm{CO}_{2}+\mathrm{H}_{2} \mathrm{O}$ ambients, we measured C 1s (Figure 5-A), Mn 2p (Figure 5-B), O 1s (Figure 5-C) and Zr 3d (Figure 5-D) XPS spectra as well as Mn L-edge (Figure 6-A) and O K-edge (Figure 6-B) NEXAFS spectra under applied potential. In the presence of $\mathrm{CO}_{2}$, both without and with $\mathrm{H}_{2} \mathrm{O}$, the $\mathrm{C}$ 1s spectra (Figure 5-A) measured at OCP show the presence of a C deposit. The well-defined peak at $284.5 \mathrm{eV}$ corresponds to a carbon deposit [41]. The presence of carbon deposits at high temperature $\left(600^{\circ} \mathrm{C}\right)$ at the surface of the Mn pristine electrode under OCP conditions can be ascribed to accumulation of unreacted carbon stemming from dissociation of gas-phase molecules and, more likely, to carbon segregation from the bulk of the metallic electrode. This latter process is indeed well-known and 
widely exploited to grow carbidic and graphene layers on metal surfaces by thermal treatment of bulk-dissolved carbon phases [42]. The energy barrier for carbon oxidation on the MnO electrode's surface is higher than the thermal energy available at $600 \mathrm{~K}$, where $\mathrm{MnO}$ is indeed stable [43], and unreactive [44]. Therefore, carbidic phases and/or carbon deposits accumulate at the electrode surface and are not removed. Application of anodic polarisation (in the Figure we show data corresponding to $2 \mathrm{~V}$ ) results in the complete removal of $\mathrm{C}$ via oxidation and gasification, due to the scavenging action of nascent $\mathrm{O}_{2}$. In fact, as the oxygen evolution reaction starts upon application of the potential, indeed, carbon is readily removed. Stabilisation of intermediates like carbonate species is excluded on the basis of their temperature stability [45], and also on both $\mathrm{C}$ and $\mathrm{O}$ 1s data, since spectral features of $\mathrm{CO}_{3}{ }^{-}$are not observed (they should be expected around 289 and $532.5 \mathrm{eV}$, respectively) [45]. It is worth noting that at $4 \mathrm{~V}$ the $\mathrm{C} 1 \mathrm{~s}$ peak appears again (an example is reported as the inset in Figure 5-D), without an electrochemical shift, as a result of Mn anode damaging, causing the electrode to be locally at OCP. The lack of an electrochemical shift in these conditions is confirmed also by the Mn $2 p$ and $\mathrm{O}$ 1s spectra (not shown, for brevity). In fact, owing to pitting and Mn surface diffusion at high applied potential (see also Figure 2, Panels B and C), islands form that are electrically disconnected from the external circuit and thereby, locally at OCP. We observed the same behaviour also with Ni electrodes in SOFC-related studies [3]. This result is correlated to the well know SOEC anode damaging mode by mechanical failure of the YSZ electrolyte in the neighbourhood of the $\mathrm{O}_{2}$-evolving anode (see also Section 3.1.3).

The potential-dependent $\mathrm{Mn} 2 \mathrm{p}$ spectra recorded in $\mathrm{CO}_{2}$ ambient are shown in Figure 5-B after alignment of the binding energies with respect to the OCP values. The spectral shapes at the different potentials and gas ambients investigated are essentially identical and we are not showing them for brevity. The relative intensity variations between OCP and $2 \mathrm{~V}$ anticorrelate with the amount of $\mathrm{C}$ present at the electrode surface, while the lower intensity found at $4 \mathrm{~V}$ can be explained with the disruption of the Mn patch and diffusion of Mn to the electrolyte zone (see Figure 2 Panels B.1-B.3), that decrease the overall amount of Mn present in the analysed spot. Both 
the shape of the main $2 p_{3 / 2}$ peak at ca. $641 \mathrm{eV}$ and the presence of the shake-up shoulder at ca. 647 $\mathrm{eV}$ lead to the unambiguous identification of the presence of $\mathrm{MnO}$ at the electrode $[40,41,43,46$, 47].

Nevertheless, since several Mn-oxides exist that are compatible with our operating conditions and exhibit significant multiplet splitting and/or shake-up features, a definitive assignment of the relative amount of $\mathrm{MnO}$ and other oxides is not possible on the basis of XPS data alone, and NEXAFS data can provide more insight. A representative selection of Mn L-edge NEXAFS spectra is reported in Figure 6-A: identical spectra were measured under different conditions, but are not shown for brevity. Our spectra are exactly the same as literature results and can be straightforwardly interpreted by comparison with published data $[48,49]$ : we can thus conclude that, regardless of the gas composition, $\mathrm{MnO}$ is found in $\mathrm{OCP}$ conditions while $\mathrm{Mn}_{3} \mathrm{O}_{4}$ forms under anodic polarisation.

Figure 5-C shows the potential-dependent $\mathrm{O} 1 \mathrm{~s}$ spectra recorded at the $\mathrm{Mn}$ electrode in all gas ambients under investigation, after alignment of the binding energies with respect to the OCP value. In $\mathrm{CO}_{2}$ ambient, two main features at ca. 530.2 and $531.4 \mathrm{eV}$ can be identified at all investigated potentials, while a third one at ca. $532.6 \mathrm{eV}$ appears in the presence of $\mathrm{H}_{2} \mathrm{O}$, the relative intensity of which is positively correlated with the amount of water in the gas phase. The binding energies of the three peaks can be assigned, respectively, to $\mathrm{Mn}$ oxide, $\mathrm{C}-\mathrm{O}$ and $\mathrm{H}-\mathrm{O}$ moieties. The relative intensities of the $\mathrm{O} 1 \mathrm{~s}$ peaks are also negatively and positively correlated with those of the $\mathrm{C} 1 \mathrm{~s}$ and Mn 2p peaks, coherently with the $\mathrm{C}$ surface coverage discussed above. NEXAFS O K-edge spectra measured under the same conditions are shown in Figure 6-B. These spectra contain a multiplicity of features, that correspond to species that are well known from the literature and, again, can be assigned by comparison with published data [50-53]. For the present purpose, we reckon that it is adequate to carry out this comparison by simply marking the energy positions of the key features of the relevant literature species. All spectra show a broad structure in the range $535-538 \mathrm{eV}$ that can be assigned to gas-phase $\mathrm{CO}$ (feature at ca. $535.7 \mathrm{eV}$ ) and $\mathrm{CO}_{2}$ (feature at ca. $537.1 \mathrm{eV}$ ) [50-52]; this assignment is further confirmed by the data collected simultaneously in the total yield mode 
(not reported, for brevity), emphasising the gas-phase response. Notwithstanding these strong gasphase contributions to the $\mathrm{O}$ K-edge spectra, the features of the two Mn oxides can be ascertained [53]. In fact, the distinctive $\mathrm{Mn}_{3} \mathrm{O}_{4}$ signature at ca. $530.5 \mathrm{eV}$ appears only under anodic polarization, independently of the gas ambient, coherently with Mn L-edge measurements (Figure 6-A) and in matching with our XPS results (Figure 5-C). In the presence of $\mathrm{H}_{2} \mathrm{O}$ an extra feature appears at ca. $534.5 \mathrm{eV}$, corresponding to gas-phase $\mathrm{H}_{2} \mathrm{O}$ and contributing to the overall gas-phase background.

The $\mathrm{Zr} 3 \mathrm{~d}$ spectra, measured within the Mn patch as a function of applied cell potential and aligned with respect to OCP values, are reported in Figure 5-D. The intensity of the spectra increases from OCP conditions to $2 \mathrm{~V}$, as a result of $\mathrm{C}$ removal by oxidation. At $4 \mathrm{~V}$ notable spectral changes are found, that can be ascribed to the formation of $\mathrm{ZrC}$ [54-57], related to anode damaging. Correspondingly, in the $\mathrm{C} 1 \mathrm{~s}$ spectra (see inset), in addition to the dominating carbon deposit peak A at $284.5 \mathrm{eV}$, at $4 \mathrm{~V}$ another peak $\mathrm{B}$ is observed at $281.9 \mathrm{eV}$, that can also be explained with $\mathrm{ZrC}$ formation [54-56]. This damaging mode is due to the formation of reactive free $\mathrm{Zr}$ sites due to zirconia reduction by loss of oxygen.

It is worth noting, that, notwithstanding the variations in EIS behavior observed during ageing of the cells (Section 3.1.2) and the morphological changes highlighted by SEM imaging (Section 3.1.2), the XPS and NEXAFS scenario is quite stable and typical spectral patterns can be straightforwardly identified, showing that the surface chemistry of the Mn electrode is typical of the investigated conditions, regardless of damaging of the electrode and electrolyte. 


\section{Conclusions}

This paper reports an in-situ near-ambient pressure XPS and NEXAFS investigation of the anodic operation of $\mathrm{Mn}$ films in a $\mathrm{Cu}|\mathrm{YSZ}| \mathrm{Mn}$ cell in $\mathrm{CO}_{2}, \mathrm{CO}_{2} / \mathrm{H}_{2} \mathrm{O}$ and $\mathrm{H}_{2} \mathrm{O}$ ambients at $600^{\circ} \mathrm{C}$, complemented with electrochemical measurements and SEM characterisation. The results complete the set of in situ XPS measurements with solid-electrolyte model electrochemical cells operated at high temperature moving from high vacuum $\left(10^{-6} \div 10^{-5}\right.$ mbar $)[2-4,18-20]$ to near-ambient pressure conditions and demonstrate the viability of such studies and the additional information that can be obtained adding NEXAFS. The Mn $2 \mathrm{p}$ and O 1 s core level XPS and the Mn L- and O K- edge NEXAFS data show that the chemical state of Mn changes from $\mathrm{MnO}$ at OCP to $\mathrm{Mn}_{3} \mathrm{O}_{4}$ under anodic polarisation, independently on the gas ambient. The $\mathrm{C} 1 \mathrm{~s}$ spectra measured in $\mathrm{CO}_{2}$ and $\mathrm{CO}_{2} / \mathrm{H}_{2} \mathrm{O}$ ambients reveal formation of a carbon depositon the Mn electrode at OCP, which can be oxidatively removed by applying anodic polarisations. The observed potential-dependent surface chemistry is typical for Mn anodes in contact with YSZ and, apart from the C deposition at OCP in the presence of $\mathrm{CO}_{2}$, we confirmed that the electrochemistry is essentially independent on the gas phase composition. Another interesting finding is that the cell damaging, evidenced by EIS and SEM data, also exerts a negligible effect, provided the investigated part of the electrode is under electrochemical control. Operation at high anodic polarisations causes formation of ZrC from YSZ and gives rise to electronically insulated Mn-containing islands, exhibiting local OCP behaviour, both processes leading to cell degradation. Future work will employ cells featuring more complex materials of practical interest for SOFC and SOEC technology and will also address the less material demanding cathodic operation, but surely rewarding from the point of view of electrochemical materials science. 


\section{Acknowledgements}

i) Measurements were carried out at the ISISS beamline of BESSY-II at Helmholtz-Zentrum Berlin. We wish to thank HZB for the allocation of synchrotron radiation beamtime and the ISISS Staff Members for their highly qualified assistance during the beamtime. The research leading to these results has received funding from the European Community's Seventh Framework Programme (FP7/2007-2013) under grant agreement $n .^{\circ} 312284$.

ii) Erik Vesselli acknowledges financial support from MIUR through project: Futuro in Ricerca FIRB 2010 no. RBFR10J4H7.

\section{References}

[1] R. Knibbe,A. Hauch, J. Hjelm, S. D. Ebbesen, M. Mogensen, Durability of Solid Oxide Cells, Green 1 (2011) 141-169.

[2] B. Bozzini, E. Tondo, M. Amati, M. Kazemian, L. Gregoratti, M. Kiskinova, In Situ X-Ray Spectromicroscopy Investigation of the Material Stability of SOFC Metal Interconnects in Operating Electrochemical Cells, ChemSusChem 4 (2011)1099-1103.

[3] B. Bozzini, M. Amati, L. Gregoratti, M. K. Abyaneh, M. Prasciolu, A. L.Trygub, Maya Kiskinova' Micro scale evolution of surface chemistry and morphology of the key components in operating hydrocarbon-fuelled SOFC, J. Phys. Chem. C 116 (2012) 23188-23193.

[4] B. Bozzini, M. Amati, L. Gregoratti, M. Kazemian, M. Prasciolu, E. Tondo, A.L.Trygub, M. Kiskinova, In situ electrochemical X-ray spectromicroscopy investigation of the reduction/reoxidation dynamics of Ni-Cu Solid Oxide Fuel Cell anodic material in contact with a $\mathrm{Cr}$ interconnect in $2 \times 10^{-6} \mathrm{mbar}_{2}$, J. Phys. Chem. C 116 (2012) 7243-7248.

[5] R. Knibbe, M.I. Traulsen, A. Hauch, S.D. Ebbesen, M. Mogensen, Solid Oxide Electrolysis Cells: Degradation at High Current Densities, J. Electrochem. Soc. 157 (2010) B1209-B1217. 
[6] B. Bozzini, E. Tondo, P. Raffa, M. Boniardi, Electrodeposition of $\mathrm{Y}_{2} \mathrm{O}_{3}$-Au composite coatings for SOFC interconnects: in situ monitoring of film growth by surface-enhanced Raman spectroscopy, Transactions of the Institute of Metal Finishing 90 (2012) 30-37.

[7] E. Tondo, M. Boniardi, D. Cannoletta, M. D'Elia, L. D'Urzo, B. Bozzini, Electrodeposition of NiO/YSZ from hydroalcoholic solutions containing Chitosan, Surface \& Coatings Technology 203 (2009) 3427-3434.

[8] E. Tondo, M. Boniardi, D. Cannoletta, M. Federica De Riccardis, B. Bozzini, Electrodeposition of Yttria-Cobalt-oxide and Yttria/Gold coatings onto ferritic stainless steel for SOFC interconnects, J. Power Sources 195 (2010) 4772-4778.

[9] J.R. Mawdsley, D.J. Carter, J.A. Kropf, B. Yildiz, V.A. Maroni, Post-test evaluation of oxygen electrodes from solid oxide electrolysis stacks, Int. J. Hydrogen En. 34 (2009) 4198-4207.

[10] K. Chen, N. Ai, S.P. Jiang, Development of (Gd, Ce) $\mathrm{O}_{2}$-impregnated (La, Sr) $\mathrm{MnO}_{3}$ anodes of high temperature solid oxide electrolysis cells, J. Electrochem. Soc. 157 (2010) P89-P94.

[11] P. Kim-Lohsoontorn, D.J.L. Brett, N. Laosiripojana, Y.M. Kim, J.M. Bae, Performance of solid oxide electrolysis cells based on composite $\mathrm{La}_{0.8} \mathrm{Sr}_{0.2} \mathrm{MnO}_{3-\delta}$-yttria stabilized zirconia and $\mathrm{Ba}_{0.5} \mathrm{Sr}_{0.5} \mathrm{Co}_{0.8} \mathrm{Fe}_{0.2} \mathrm{O}_{3-\delta}$ oxygen electrodes, Int. J. Hydrogen En. 35 (2010) 3958-3966.

[12] M.A. Laguna-Bercero, R. Campana, A. Larrea, J.A. Kilner, V.M. Orera, Electrolyte degradation in anode supported microtubular yttria stabilized zirconia-based solid oxide steam electrolysis cells at high voltages of operation, J. Power Sources 196 (2011) 8942-8947.

[13] S.N. Rashkeev, M.V. Glazoff, Control of oxygen delamination in solid oxide electrolyzer cells via modifying operational regime, Appl. Phys. Lett. 99 (2011) 173506-173513.

[14] S.N. Rashkeev, M.V. Glazoff, Atomic-scale mechamisms of oxygen electrode delamination in solid electrolyzer cells, Int. J. Hydrogen En. 37 (2012) 1280-1291.

[15] J. Kim, H.-I. Ji, H.P. Dasari, D. Shin, H. Song, J.-H. Lee, B.-K. Kim, H.-J. Je, H.-W. Lee, K.J. Yoon, Degradation mechanism of electrolyte and air electrode in solid oxide electrolysis cells operating at high polarization, Int. J. Hydrogen Energy 38 (2013) 1225-1235. 
[16] J. Mizusaki, N. Mori, H. Takai, Y. Yonemura, H. Minamiue, H. Tagawa, M. Dokiya, H. Inaba, K. Naraya, T. Sasamoto, T. Hashimoto, Oxygen nonstoichiometry and defect equilibrium in the perovskite-type oxides $\mathrm{La}_{1-\mathrm{x}} \mathrm{Sr}_{\mathrm{x}} \mathrm{MnO}_{3-\mathrm{d}}$, Solid State Ionics 2000;129:163-77.

[17] M. Backhaus-Ricoult, K. Adib, T.S. Clair, B. Luerssen, L. Gregoratti, A. Barinov, In-situ study of operating SOFC LSM/YSZ cathodes under polarization by photoelectron microscopy, Solid State Ionics 179 (2008) 891-895.

[18] B. Bozzini, M.K. Abyaneh, M. Amati, A. Gianoncelli, L. Gregoratti, B. Kaulich, M. Kiskinova, Soft X-ray imaging and spectromicroscopy: new insights in chemical state and morphology of key components in operating fuel cells, Chemistry-A European Journal 18 (2012) 10196-10210.

[19] B. Bozzini, M. Amati, L. Gregoratti, C. Mele, M. K. Abyaneh, M. Prasciolu, M. Kiskinova, In situ photoelectron microspectroscopy during the operation of a single-chamber SOFC, Electrochem. Comm. 24 (2012) 104-107.

[20] B. Bozzini, M. Amati, L. Gregoratti, M. Kiskinova, In-situ Photoelectron Microspectroscopy and Imaging of Spontaneous Electrochemical Processes at the Electrodes of a Self-Driven Single Cell,Science Reports 3 (2013) 2848 (5 pages).

[21] C. J. Corcoran, H. Tavassola, M. A. Rigsbya, P.S. Bagusb, A. Wieckowski, Application of XPS to study electrocatalysts for fuel cells, J. Power Sources 195 (2010) 7856-7879.

[22] F. El Gabaly, K.F. McCarty, H. Bluhm, A.H. McDaniel, Phys. Chem.Chem. Phys 15 (2013) 8334-8341.

[23] C. Zhang, M.E. Grass, A.H. McDaniel, S.C. DeCaluwe, F. El Gabaly, Z. Liu, K.F. McCarty, R.L. Farrow, M.A. Linne, Z. Hussain, G.S. Jackson, H. Bluhm, B.W. Eichhorn, Measuring fundamental properties in operating solid oxide electrochemical cells by using in situ X-ray photoelectron spectroscopy, Nature Materials, 9 (2010) 944-949.

[24] C. Zhang, M. E. Grass, Y. Yu, K. J. Gaskell, S. C. DeCaluwe, R. Chang, G. S. Jackson, Z. Hussain, H. Bluhm, B. W. Eichhorn, Z. Liu, Multielement Activity Mapping and Potential Mapping 
in Solid Oxide Electrochemical Cells through the use of operando XPS, ACS Catal. 2 (2012) 22972304.

[25] T. Hibino, Y. Kuwahara, S. Wang, Effect of Electrode and Electrolyte Modification on the Performance of One - Chamber Solid Oxide Fuel Cell, J. Electrochem. Soc. 146 (1999) 2821-2826.

[26] C. Gaudillere, L. Navarrete, J.M Serra, Syngas production at intermediate temperature through $\mathrm{H}_{2} \mathrm{O}$ and $\mathrm{CO}_{2}$ electrolysis with a $\mathrm{Cu}$-based solid oxide electrolyser cell, Int. J. Hydrogen Energy 39 (2014) 3047-3054.

[27] T.-J. Huang, C.-L. Chou, Electrochemical $\mathrm{CO}_{2}$ reduction with power generation in SOFCs with Cu-added LSCF-GDC cathode, Electrochem. Comm. 11 (2009) 1464-1467.

[28] http://www.abc.chemistry.bsu.by/vi/analyser/

[29] R. Barfod, M. Mogensen, T. Klemenso, A. Hagen, Y. L. Liu, P. V. Hendriksen, Detailed characterization of anode-supported SOFCs by impedance spectroscopy, J. Electrochem. Soc. 154, (2007) B371-B378.

[30] A. Nechache, M. Cassir, A. Ringuedé, Solid oxide electrolysis cell analysis by means of electrochemical impedance spectroscopy: A review, J. Power Sources 258 (2014) 164-181.

[31] S. D. Ebbesen, R. Knibbe, M. Mogensen, Co-Electrolysis of Steam and Carbon Dioxide in Solid Oxide Cells, J. The Electrochem. Soc. 159 (2012) F482-F489.

[32] R. Xing, Y. Wang, Y. Zhu, S.Liu, C. Jin, Co-electrolysis of steam and $\mathrm{CO}_{2}$ in a solid oxide electrolysis cell with $\mathrm{La}_{0.75} \mathrm{Sr}_{0.25} \mathrm{Cr}_{0.5} \mathrm{Mn}_{0.5} \mathrm{O}_{3-\delta}-\mathrm{Cu}$ ceramic composite electrode, J. Power Sources 274 (2015) 260-264.

[33]http://www.helmholtzberlin.de/pubbin/igama_output?modus=einzel\&Sprache=de\&gid=1607\&t ypoid $=50740$

[34] S. Doniach, M. Sunjic, Many-electron singularity in X-ray photoemission and X-ray line spectra from metals, J. Phys. C 3 (1970) 285-291.

[35] L. Bi, E. Traversa, A chemically stable electrolyte with a novel sandwiched structure for proton-conducting solid oxide fuel cells (SOFCs), Electrochem. Commun. 36 (2013) 42-45. 
[36] L. Bi, S. Boulfrad and E. Traversa, Steam electrolysis by solid oxide electrolysis cells (SOECs) with proton-conducting oxides, Chem. Soc. Rev. 43 (2014) 8255-8270.

[37] A. Brisse, J. Schefold, and M. Zahid, High temperature water electrolysis in solid oxide cells, Int. J. Hydrogen Energy, 33 (2008) 5375.

[38] J. Schefold, A. Brisse, M. Zahid, Electronic Conduction of Yttria-Stabilized Zirconia Electrolyte in Solid Oxide Cells Operated in High Temperature Water Electrolysis, J. Electrochem. Soc. 159 (2009) B897-B904.

[39] Z.L. Zhan, W. Kobsiriphat, J.R. Wilson, M. Pillai, S.A. Barnett, Syngas Production By Coelectrolysis of $\mathrm{CO}_{2} / \mathrm{H}_{2} \mathrm{O}$ : The Basis for a Renewable Energy Cycle, Energy\&Fuels 23 (2009) 3089-3096.

[40] E.-C. Shin, P.-A. Ahn, H.-H. Seo, J.-M. Jo, S.-D. Kim, S.-K. Woo, J. H. Yu, J. Mizusaki, J.-S. Lee, Polarization mechanism of high temperature electrolysis in a Ni-YSZ/YSZ/LSM solid oxide cell by parametric impedance analysis, Solid State Ionics 232 (2013) 80-96.

[41] E. Vesselli, E. Monachino, M. Rizzi, S. Furlan, X. Duan, C. Dri, A. Peronio, C. Africh, P. Lacovig, A. Baldereschi, G. Comelli, M. Peressi, Steering the Chemistry of Carbon Oxides on a NiCu Catalyst, ACS Catal. 3 (2013) 1555-1559.

[42] N. Liu, L. Fu, B. Dai, K. Yan, X. Liu, R. Zhao, Y. Zhang, Z. Liu, Universal segregation growth approach to wafer-size graphene from non-noble metals, Nano Lett. 11 (2011) 297-303.

[43] M. Oku, K. Hirokawa, S. Ikeda, X-ray photoelectron spectroscopy of manganese-oxygen systems, J. Electron Spectrosc. 7 (1975) 465-473.

[44] L.C. Wang, Q.Liu, X.S. Huang, Y.M. Liu, Y. Cao, K.N. Fan, Gold nanoparticles supported on manganese oxides for low-temperature CO oxidation. Appl. Catal., B 88 (2009) 204-212.

[45] M. Kilo, J. Weigel, A. Wokaun, R.A. Koeppel, A. Stoeckli, A. Baiker, Effect of the addition of chromium- and manganese oxides on structural and catalytic properties of copper/zirconia catalysts for the synthesis of methanol from carbon dioxide. J. Mol. Catal. A Chem. 126 (1997) 169-184. 
[46] H.W. Nesbitt, D. Banerjee, Interpretation of XPS Mn(2p) spectra of Mn oxyhydroxides and constraints on the mechanism of $\mathrm{MnO}_{2}$ precipitation, American Mineraolgist 83 (1998) 305-315.

[47] M.C. Biesinger, B.P. Payne, A.P. Grosvenor, L.W.M. Lau, A.R. Gerson, R.S.C. Smart, Resolving surface chemical states in XPS analysis of first row transition metals, oxides and hydroxides: Cr, Mn, Fe, Co and Ni, Appl. Surf. Sci. 257 ( 2011) 2717-2730.

[48] B. Gilbert, B.H. Frazer, A. Belz, P.G. Conrad, K.H. Nealson, D. Haskel, J.C. Lang, G. Srajer, G. De Stasio, Multiple Scattering Calculations of Bonding and X-ray Absorption Spectroscopy of Manganese Oxides, J. Phys. Chem. A 107 (2003) 2839-2847.

[49] S. Kobayashi, I.R.M. Kottegoda, Y. Uchimoto, M. Wakihara, XANES and EXAFS analysis of nano-size manganese dioxide as a cathode material for lithium-ion batteries, J. Mater. Chem, 14 (2004) 1843-1848.

[50] O. Björneholm, A. Nilsson, E. Zdansky, A. Sandell, B. Hernnäs, H. Tillborg, J. Andersen, N. Mårtensson, Phys. Rev. B 46 (1992) 10353-10365.

[51] O. Björneholm, A. Nilsson, E. Zdansky, A. Sandell, H. Tillborg, J. Andersen, N. Mårtensson, Phys. Rev. B 47 (1993) 2308-2319.

[52] L. Triguero, L.G.M. Pettersson, Calculations of near-edge x-ray-absorption spectra of gasphase and chemisorbed molecules by means of density-functional and transition-potential theory Phys. Rev. B 58 (1998) 8097-8110.

[53] C.P. Schwartz, J.S. Uejio, A.M. Duffin, W.S. Drisdell, J.D. Smith, R.J. Saykally, Soft X-ray absorption spectra of aqueous salt solutions with highly charged cations in liquid microjets, Chemical Physics Letters 493 (2010) 94-96.

[54] Z. Song, X. Bao, U. Wild, M. Muhler, G. Ertl, Oxidation of amorphous Ni-Zr alloys studied by XPS, UPS, ISS and XRD, Applied Surface Science 134 (1998) 31-38.

[55] M. Balaceanu, M. Braic, V. Braic, A. Vladescu, C. C. Negrila, Surface Chemistry of plasma deposited ZrC hard coatings, J. Optoelectronics and Advanced Materials 7 (2005) 2557 - 2560. 
[56] Y. F. Zheng, X.L. Liu, H.F. Zhang, Properties of Zr-ZrC-ZrC/DLC gradient films on TiNi alloy by the PIIID technique combined with PECVD, Surface \& Coatings Technology 202 (2008) 3011-3016.

[57] J. Woo, Growth of Epitaxial Zirconium Carbide Layers using Pulsed Laser Deposition, University of Florida, Dissertation, 2005.

\section{Figure captions}

Figure 1 - The electrochemical cell: concept, fabrication and mounting in analysis chamber. (A, B) Cell concept: arrangement and dimensions of electrodes and electrolyte (schematic drawing, not to scale): (A) cross-sectional view, (B) planar view. (C) Electrochemical operating scheme and conceptual cell reactions in the ambients considered in this study: (C.1) $\mathrm{CO}_{2}$ electrolysis; (C.2) $\mathrm{CO}_{2}$ and $\mathrm{H}_{2} \mathrm{O}$ co-electrolysis; (C.3) $\mathrm{H}_{2} \mathrm{O}$ electrolysis. (D) Electrochemical cell mounted on sample holder. (E) Electrochemical sample holder with mounted cell on sample stage in analysis chamber.

Figure 2 - SEM micrographs of the Mn electrode with indication of the imaged cell zones: (A) pristine conditions; (B) after operation in $\mathrm{CO}_{2}$; (C) after operation in $\mathrm{CO}_{2} / \mathrm{H}_{2} \mathrm{O}$. (A.1), (B.1) and (C.1): typical region inside the electrolyte patch. (A.2), (B.2) and (C.2): typical holes forming a triple-phase boundary between the Mn film electrode and the underlying YSZ electrolyte. (A.3), (B.3) and (C.3): the interface between the Mn and YSZ patches of the planar cell.

Figure 3 - Electrochemical measurements carried out at $600^{\circ} \mathrm{C}, 0.5 \mathrm{mbar}$ in the indicated gas environments. (A) Linear-sweep voltammograms: scan rate: $1 \mathrm{mV} \mathrm{s}^{-1}$, WE: $\mathrm{Cu}$ electrode, $\mathrm{CE}=\mathrm{RE}$ : Mn electrode. (B)-(D) Mock-up of the analysis chamber used for calibration electrochemical experiments: (B) load-lock side, (C) viewport side, (D) operating electrochemical cell imaged 
through the viewport. (E)-(F) Electrochemical impedance spectra: (E) $|\mathrm{Z}|$ vs. frequency, (F) Nyquist plots. Bias: $2 \mathrm{~V}$, amplitude: $10 \mathrm{mV}_{\mathrm{pp}}$, WE: $\mathrm{Cu}$ electrode, $\mathrm{CE}=\mathrm{RE}$ : $\mathrm{Mn}$ electrode. Scatter: experimental points. Line: fitted spectrum. The equivalent circuit used to fit the spectra is: $\mathrm{R}_{\mathrm{ohm}}\left(\mathrm{R}_{1} \mathrm{CPE}_{1}\right)\left(\mathrm{R}_{2} \mathrm{CPE}_{2}\right)\left(\mathrm{R}_{3} \mathrm{CPE}_{3}\right)\left(\mathrm{R}_{4} \mathrm{CPE}_{4}\right)$.

Figure 4 - Electrochemical impedance spectra (EIS) measured at $600^{\circ} \mathrm{C}$ in 0.5 mbar of the indicated gases. Spectra measured at OCP at the beginning of the experiment and after the indicated periods of potentiostatic testing during spectroscopy. (A) $\mathrm{CO}_{2}$ ambient; (B) $\mathrm{CO}_{2}+\mathrm{H}_{2} \mathrm{O} 1 / 1$ and $1 / 2$ and $\mathrm{H}_{2} \mathrm{O}$ (see details on Figure). Bias: OCP, amplitude: $10 \mathrm{mV}_{\mathrm{pp}}$, WE: Cu electrode, $\mathrm{CE}=\mathrm{RE}$ : Mn electrode. Scatter: experimental points. Line: fitted spectrum. The equivalent circuits used to fit the spectra are: (A) Pristine: $\mathrm{R}_{\mathrm{ohm}}\left(\mathrm{R}_{1} \mathrm{CPE}_{1}\right)\left(\mathrm{R}_{2} \mathrm{CPE}_{2}\right)\left(\mathrm{R}_{3} \mathrm{CPE}_{3}\right)$;

Aged (2V): $\mathrm{R}_{\text {ohm }}\left(\mathrm{R}_{1} \mathrm{CPE}_{1}\right)\left(\mathrm{R}_{2} \mathrm{CPE}_{2}\right)\left(\mathrm{R}_{3} \mathrm{CPE}_{3}\right)\left(\mathrm{R}_{4} \mathrm{~W}_{4}\right)$; Aged (4 V): $\mathrm{R}_{\mathrm{ohm}}\left(\mathrm{R}_{1} \mathrm{CPE}_{1}\right)\left(\mathrm{R}_{2} \mathrm{CPE}_{2}\right)\left(\mathrm{R}_{3} \mathrm{CPE}_{3}\right)$. (B) $\mathrm{R}_{\mathrm{ohm}}\left(\mathrm{R}_{1} \mathrm{CPE}_{1}\right)\left(\mathrm{R}_{2} \mathrm{CPE}_{2}\right)\left(\mathrm{R}_{3} \mathrm{CPE}_{3}\right)\left(\mathrm{R}_{4} \mathrm{CPE}_{4}\right)$.

Figure 5 - XPS spectra recorded in the indicated gas ambients at 0.5 mbar and $600^{\circ} \mathrm{C}$ under electrochemical control. (A) C 1s; (B) Mn 2p; (C) O 1s with component fitting and (D) $\mathrm{Zr} 3 \mathrm{~d}$ : a C 1s spectrum measured at $4 \mathrm{~V}$ in $\mathrm{CO}_{2}$ gas is reported in the inset. The binding energies have been aligned with respect to the OCP value.

Figure 6 - NEXAFS spectra (XPS yield) recorded in the indicated gas ambients at $0.5 \mathrm{mbar}$ and $600^{\circ} \mathrm{C}$ under electrochemical control. (A) Mn L-edge; (B) O K-edge: the energy positions of features that are typical of the indicated species - as derived from the literature - are indicated with colour-coded bars. 


\section{Figures}

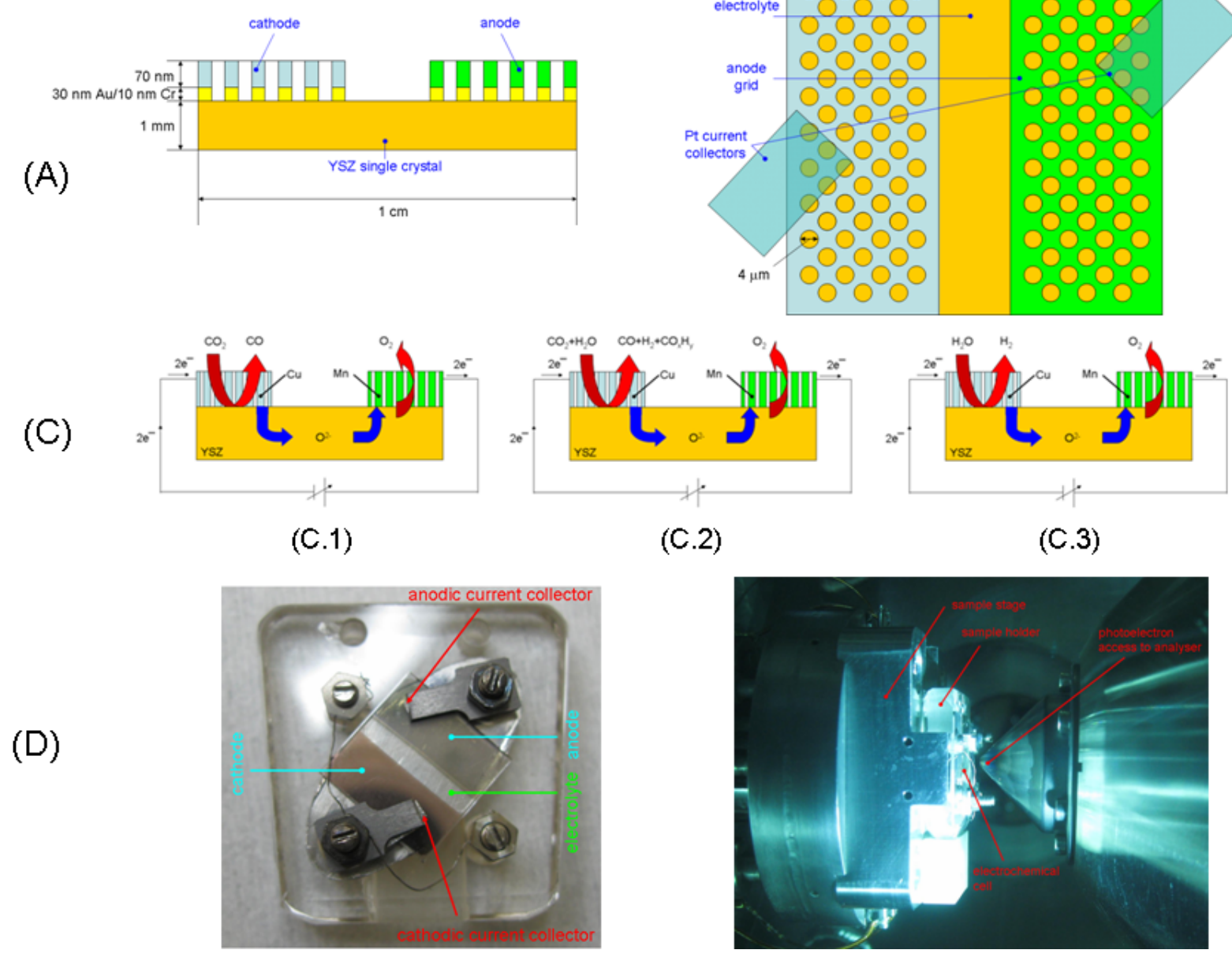

(B)

(E)

Figure 1 


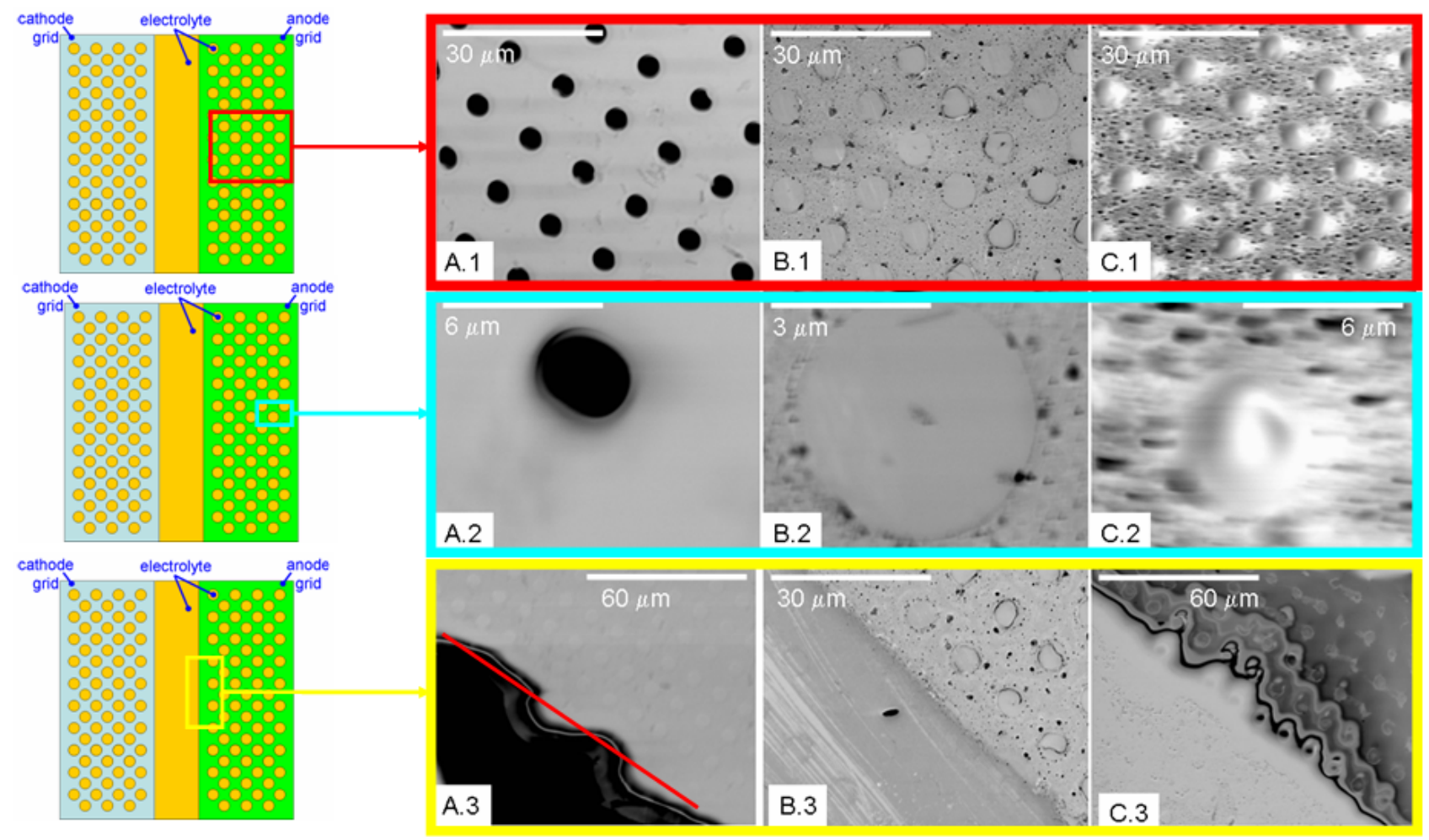

Figure 2 
(A)
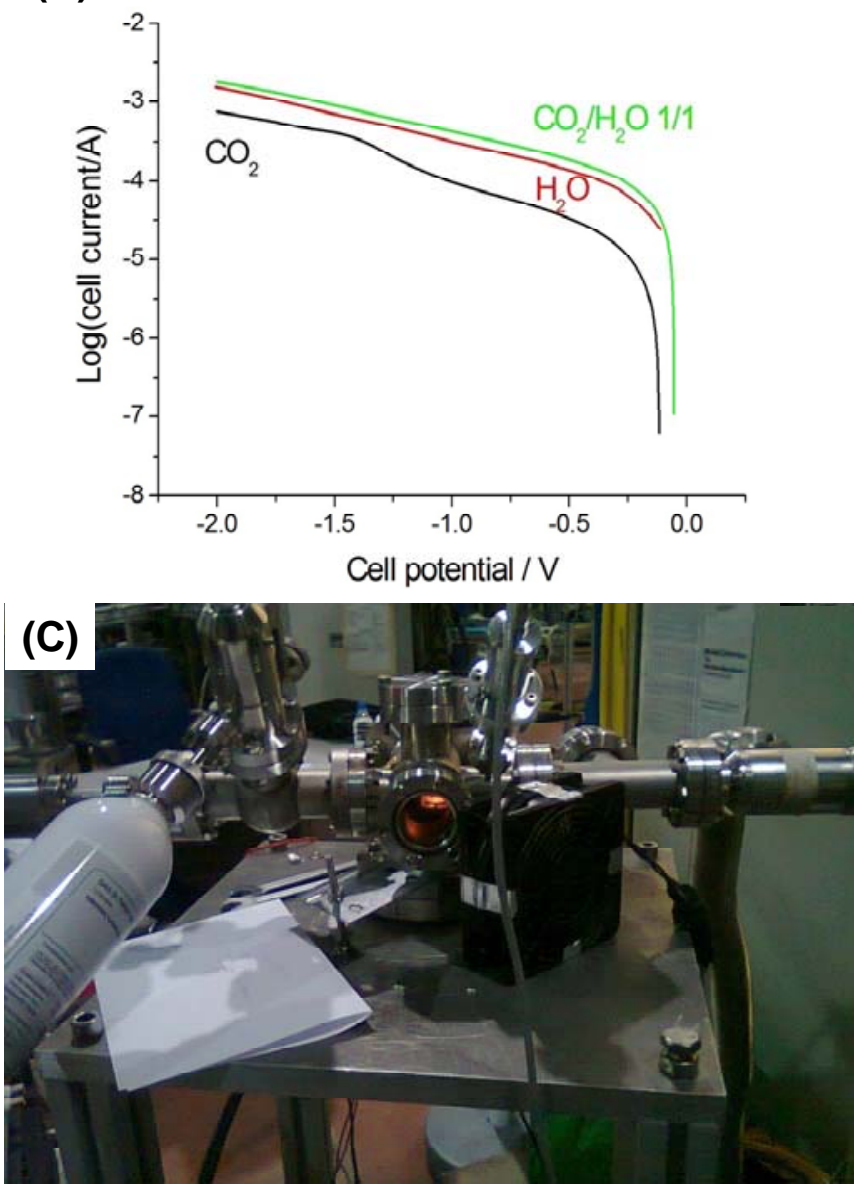

(E)

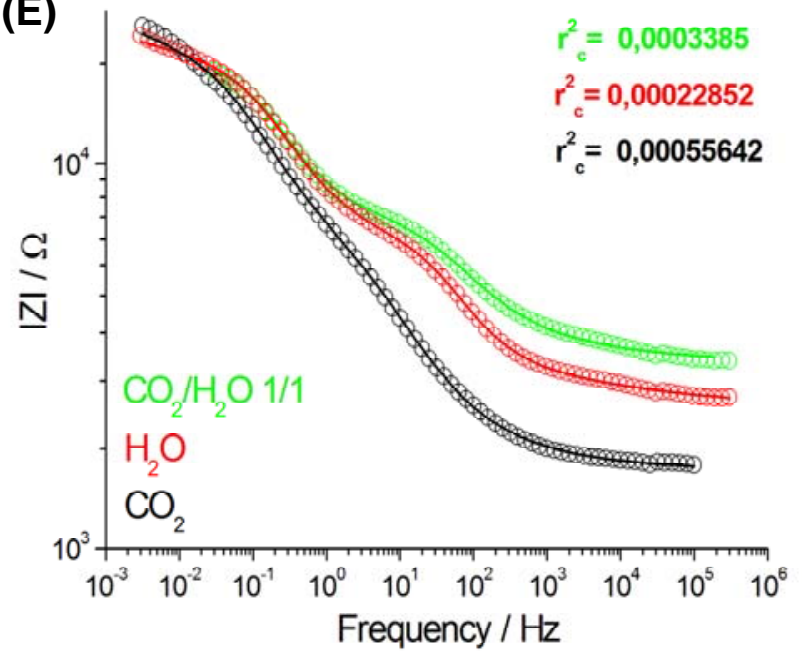

(B)

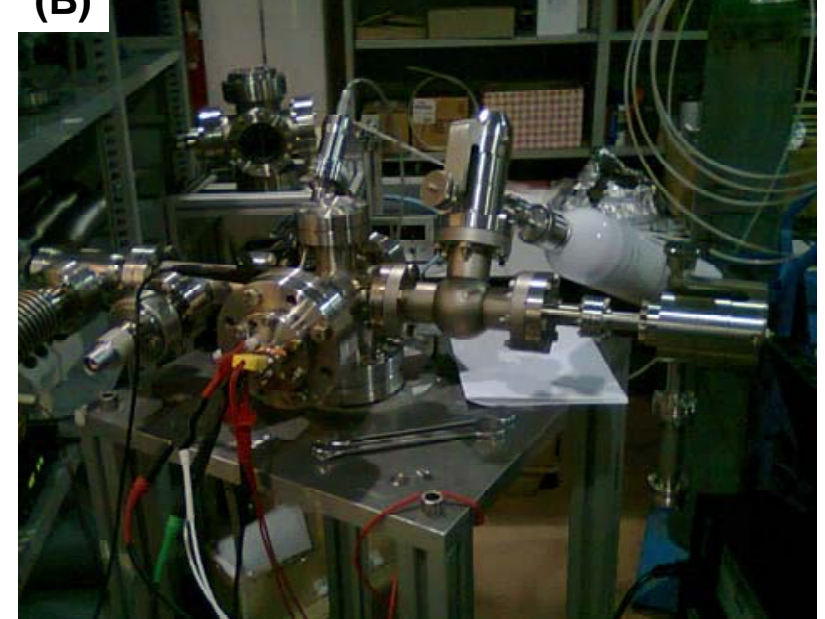

(D)

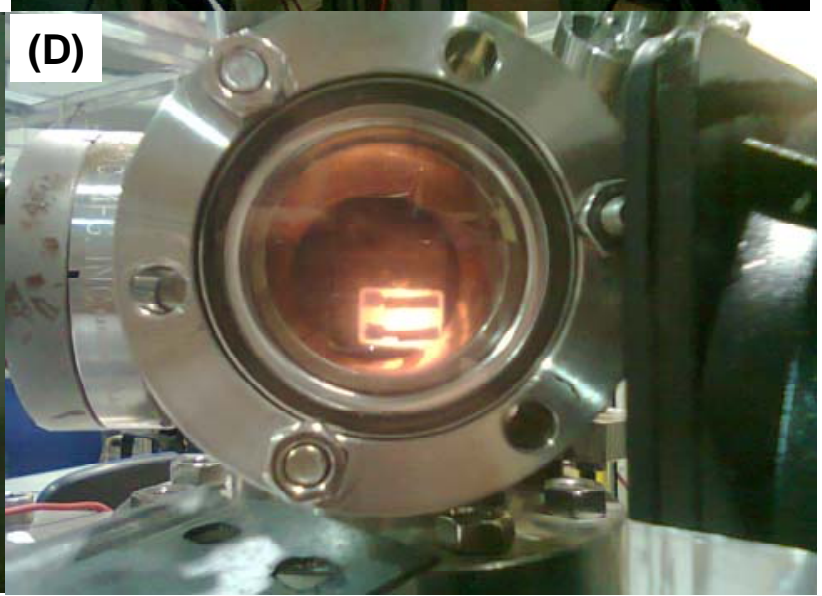

(F)

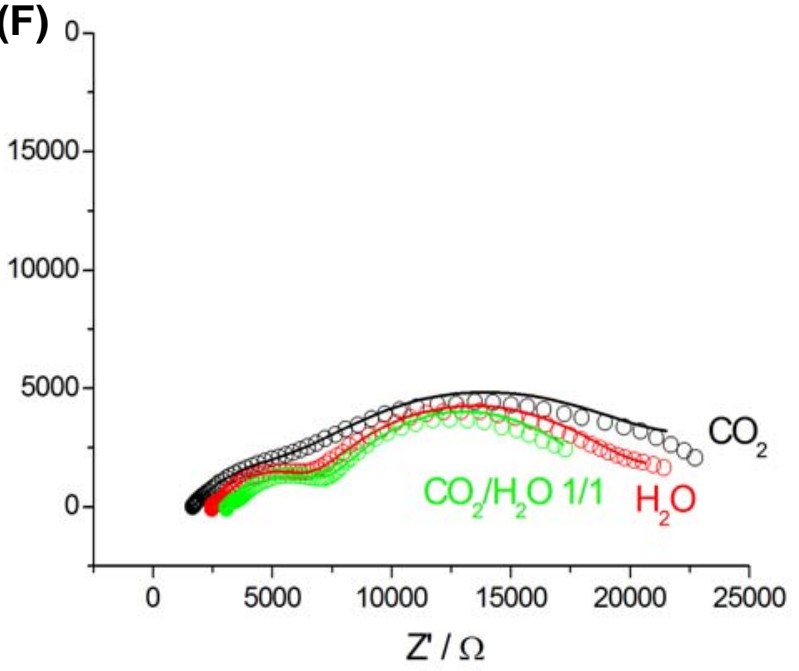

Figure 3 

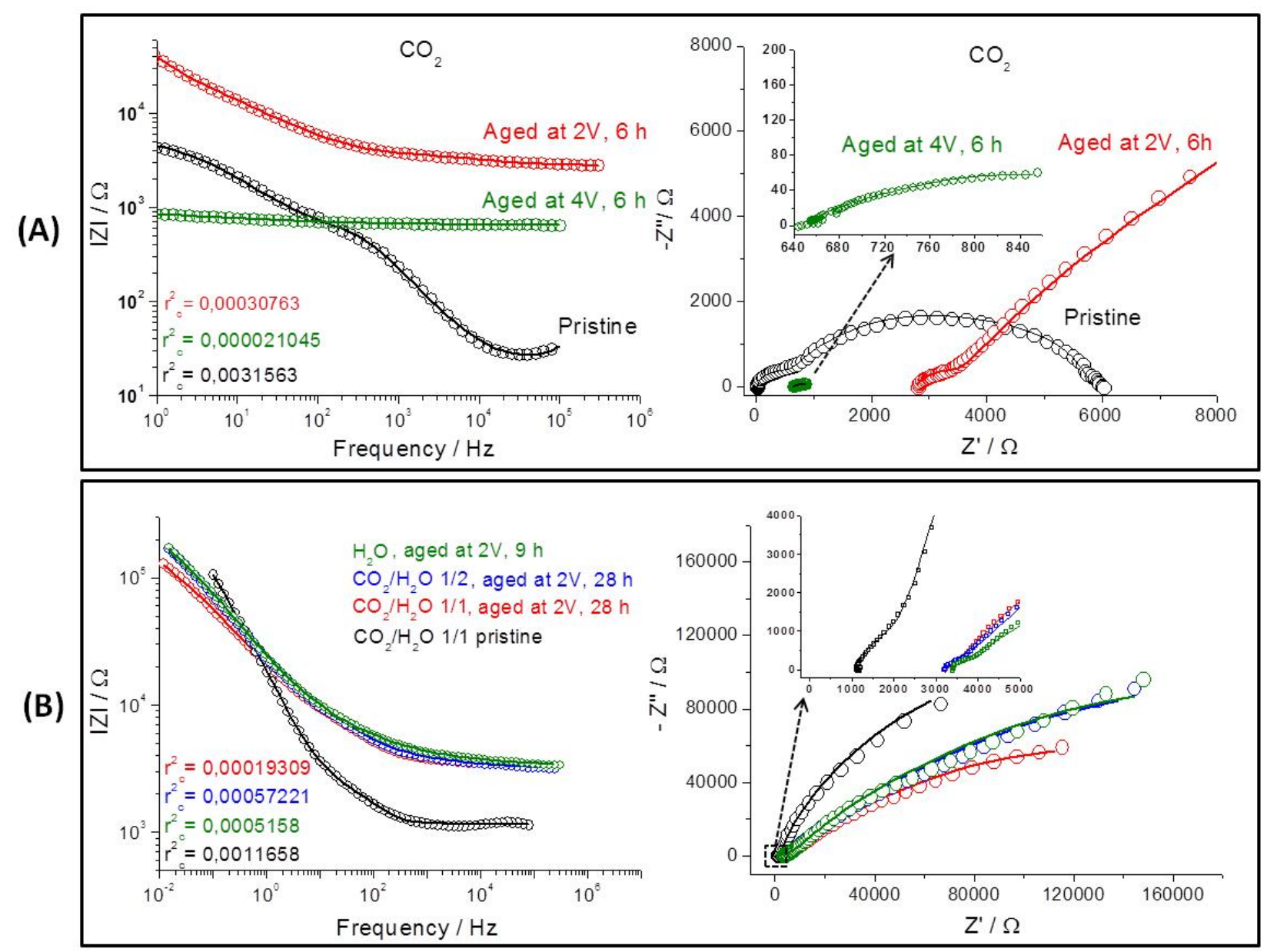

Figure 4 
(A)

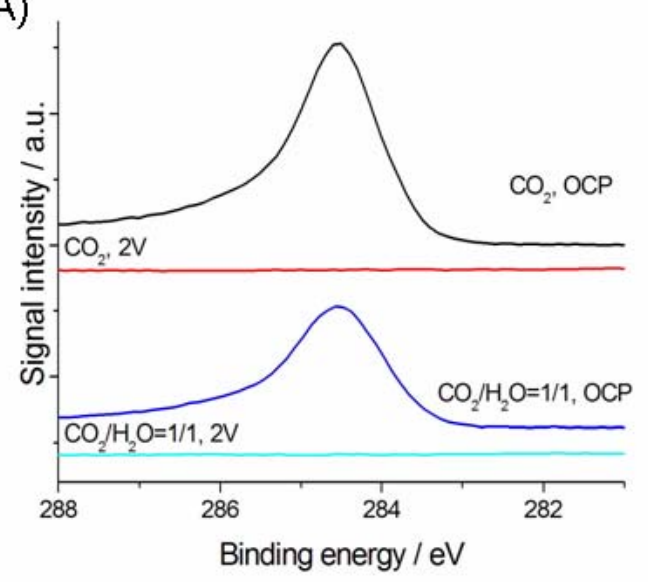

(C)

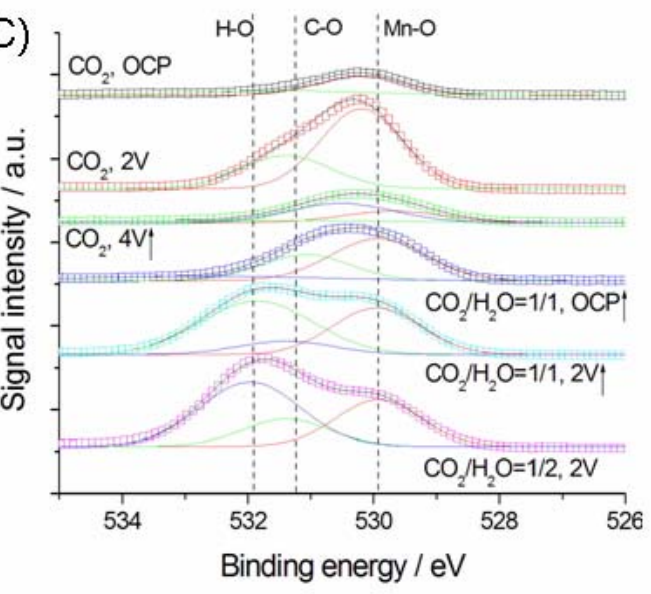

(B)
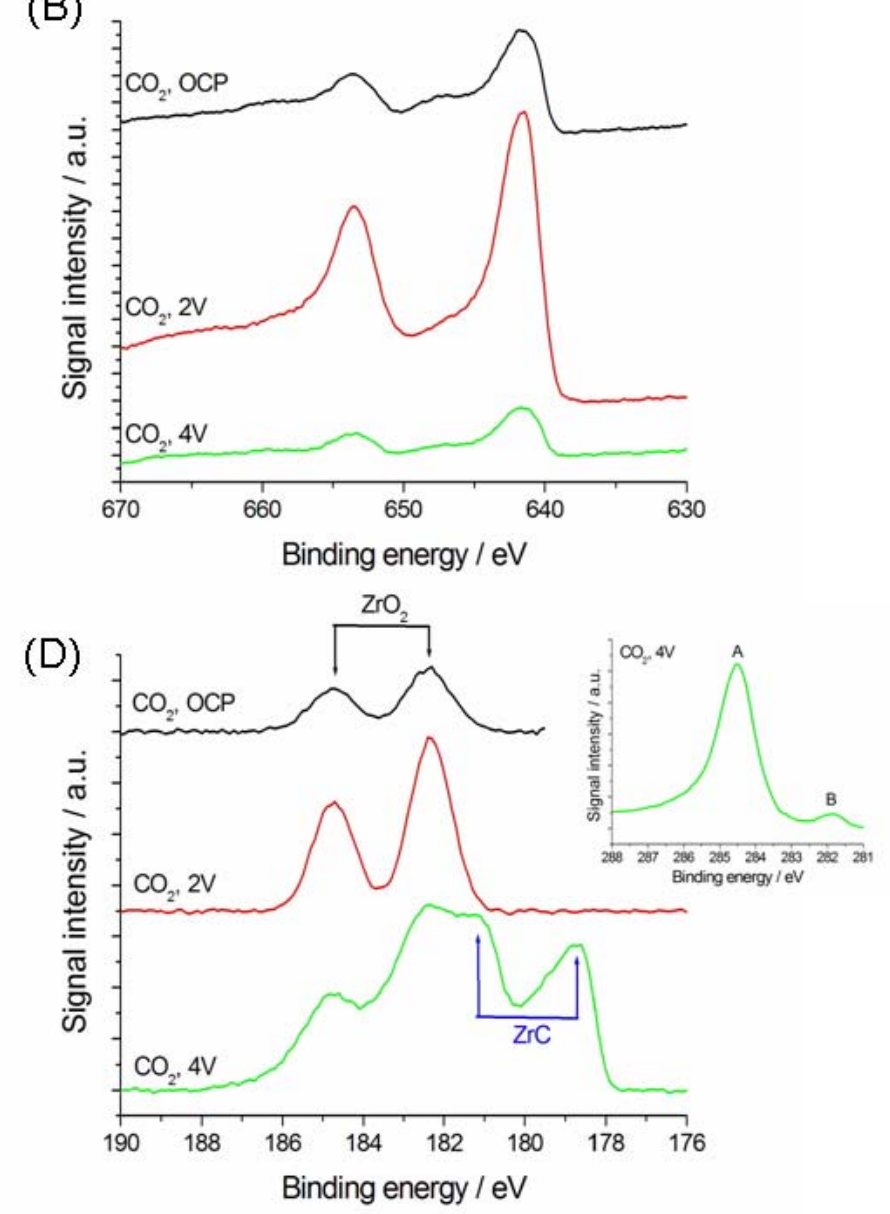

Figure 5

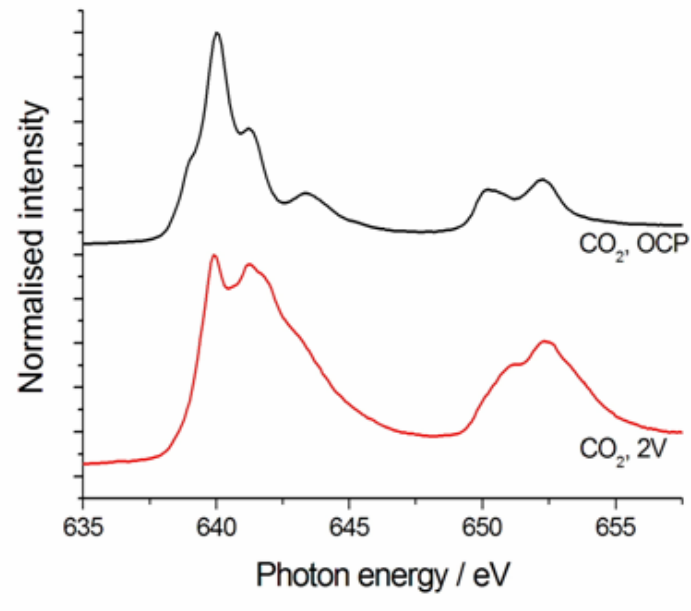

(A)

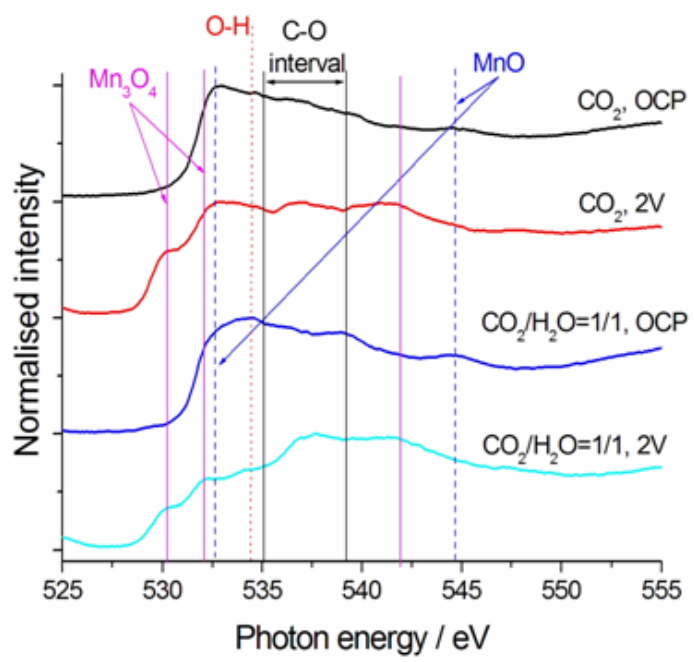

(B)

Figure 6 